\title{
Approach of Development of Electric Double Layer Capacitor for High Power and Long Life
}

\author{
Ryutaro Nozu*, Mami Nakamura*, Yutaka Matsuzawa*, Kunihiro Mitsuya*, \\ and Toshiaki Kushihara*
}

\begin{abstract}
We developed an electric double layer capacitor using an ionic liquid as the electrolyte salt for a high energy density and a life performance. The influence of the surface area of the activated carbon and the concentration of the electrolyte on the storage and life performance of the capacitor was studied. Separator can control the gas generation during the float charge of the capacitor to be able to extend the its life.

Our produced capacitor, "N's Cap", by these techniques has good performances and the storage module assembled with the cells and the external circuit was presented.
\end{abstract}

\section{Keywords: Electric Double Layer Capacitor, Ionic liquid, Activated Carbon, Specific Surface Area}

\section{INTRODUCTION}

To meet the need to reduce carbon dioxide $\left(\mathrm{CO}_{2}\right)$ emissions and the consumption of fuels worldwide, practical applications such as hybrid electric vehicles (HEVs), fuel cells (FCs), and pure electric vehicles (PEVs) have started to be produced for preventing global warming [1]-[2]. The technology for the storage of electricity has been paid significant attention, and enhancing the energy efficiency of a battery was demanded. However, this has been weak point for the conventional chemical secondary batteries such as $\mathrm{Pb}$ acid, $\mathrm{Ni}-\mathrm{Cd}, \mathrm{Ni}-\mathrm{MH}$ and $\mathrm{Li}-\mathrm{ion}$. Recently, an electric double layer capacitor (EDLC) is expected to be developed as a storage device which can be efficiently charged, and discharged to produce a high power, and used for many cycles and for a long time [3]-[7]. Many developments regarding EDLCs have been devoted to producing a good performance.

It is necessary to make the energy density higher, the power density higher, and the lifetime longer for applying to PEVs, FCVs, and HEVs. However, many techniques to increase the energy density and the power density of the EDLC would make its lifetime shorter [8]-[12]. We have developed and produced an EDLC for meeting requirements from a market.

We developed the ionic liquid [13]-[14] as an electrolyte salt of the EDLC for increasing its storage energy and extending its lifetime. Because the ionic liquid can be blended in many organic solvents at any

* Nisshinbo Industries Incorporated, Research \& Development Center, 1-2-3 Onodai, Midori-ku, Chiba, 267-0056, Japan, Tel: +043205 0792, Fax: +043205 0846, e-mail:

nozu@nisshinbo.co.jp; m-iizuka@nisshinbo.co.jp; matsuzawa@nisshinbo.co.jp; mitsuya@nisshinbo.co.jp; kushihara@nisshinbo.co.jp concentration, the necessary number of ions can be given to the EDLC without minding the solubility of the solid salt to the solvent. The electrolyte containing the developed ionic liquid which was one of quarternary ammonium salts had a better electrochemical stability than the known ionic liquids [15]. An appropriate concentration of electrolyte was chosen for our produced capacitor because it was found that the concentration of electrolyte influenced the life performance of the EDLC. The influences of the surface area of the activated carbon on the positive and negative capacitances and the life performance of the capacitor were investigated to find the appropriate surface area of it as the positive or negative active material, respectively.

Two trials for controlling undesirable side reactions on the positive and/or negative electrodes to extend the lifetime of the EDLC were carried out. The ideal EDLC was charged or discharged only by adsorbed and desorbed ions on/from the electrodes. However, there were some side reactions on the positive or/and negative electrode with gas generation when the actual EDLC was charged. The negative electrode was coated with a polymer for controlling its corrosion and the side reaction to investigate the life performance of the EDLC with it. And, the sealed EDLC with several separators was tested in the float charge test with measuring its internal pressure.

We have produced the EDLC, "N's Cap", as a new commodity with these techniques for increasing the energy density and extending the lifetime of it. Three types of capacitors with a rated voltage of $3.0 \mathrm{~V}$ and a rated capacitance from $250 \mathrm{~F}$ to $1,000 \mathrm{~F}$ were provided as the lineup. We introduced the characteristics of the EDLC cells, the storage modules assembled with the external circuit to equalizing the states of charge of the 
cells, and some examinations for application in this paper.

\section{EXPERIMENTAL}

For studying the electrolyte, propylene carbonate (PC) solutions containing $1.0 \mathrm{~mol} \cdot \mathrm{dm}^{-3}$ of one of the salts were prepared. The salts were our developed ionic liquid, N, N-diethyl-N-methyl-N-(2-methoxyethyl) ammonium tetrafluoroborate $\left(\mathrm{DEME}-\mathrm{BF}_{4}\right)$, 1-ethyl-3methylimidazolium tetrafluoroborate $\left(\mathrm{EMI}_{-} \mathrm{BF}_{4}\right)$ for comparison, tetraethylammonium tetrafluoroborate $\left(\mathrm{TEA}-\mathrm{BF}_{4}\right), \quad$ and triethylmethylammonium tetrafluoroborate $\left(\mathrm{TEMA}-\mathrm{BF}_{4}\right)$ as solid salts. The cyclic voltammetry (CV) was carried out in an electrochemical cell containing a platinum wire as a working electrode, a platinum spiral wire as a counter electrode, and a silver-silver chloride reference electrode $(\mathrm{Ag} / \mathrm{AgCl})$. The redox potential of the reference electrode was premeasured in the electrolyte using the ferrocene/ferrocinium couple as an internal standard. An electrochemical measurement system (HZ-3000, Hokuto Denko Co., Ltd.) with a potentiostat and a function generator was used for the CV.

A capacitor cell was especially designed for studying the activated carbons and the concentration of the electrolyte. One of the activated carbons with various specific surface areas, acetylene black (HS-100, DENKI KAGAKU KOGYO KABUSHIKI KAISHA), polyvinylidene fluoride -polyhexafluoropropylene copolymer $\left[-\left(\mathrm{CH}_{2} \mathrm{CF}_{2}\right)_{\mathrm{n}^{-}}\left(\mathrm{CF}_{2}-\mathrm{CFCF}_{3}\right)_{\mathrm{m}}{ }^{-}\right]$(KF-P\#9305, Kureha Co.) and poly(vinylidene)fluoride $\left[-\left(\mathrm{CH}_{2} \mathrm{CF}_{2}\right)_{\mathrm{n}^{-}}-\right]$ (KYNER\#461, Atofina Japan K.K.) were mixed in Nmethyl-2-pyrrolidone (NMP, Wako Pure Chemical Industries, Ltd.). The mixture was coated on a side of etched Al (30CB, Japan Capacitor Ind. Co., Ltd.), and the sheets coated with the materials were dried, pressed and used as the positive sheets. In the same way, the sheets coated with materials were prepared as the negative sheets. The thickness of the positive and the negative materials except for the substrate were ca. $0.10 \mathrm{~mm}$ and ca. $0.12 \mathrm{~mm}$, respectively.

The positive and negative sheets were cut into the size of $40 \mathrm{~mm} \times 20 \mathrm{~mm}$ with a tab whose size was $10 \mathrm{~mm} \times 20 \mathrm{~mm}$. The positive and negative electrodes were selected by a predetermined weight. An element with the positive electrode and the negative electrode and the reference electrode which was made by welding Al ribbon to an etched Al foil [16] alternately stacked with the polyethylene film separators (NI040A, Nippon Sheet Glass Co., Ltd.) was constructed.

After drying, the element with the reference electrode was inserted into a bag made of a thermoplastic film laminated to an aluminum sheet (DEL40H, Dai Nippon Printing Co., Ltd.), then injecting the electrolyte. For studying the electrolyte, some concentrations of the electrolyte were prepared by

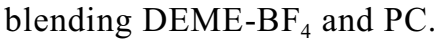

The float charge test at a constant voltage of $3.0 \mathrm{~V}$ and $70^{\circ} \mathrm{C}$ [17] was carried out for investigation of the performance of the capacitor after three charge and discharge cycles for measuring the initial capacitance at a low current of ca. 1.0C.

For investigating the influence the separator and the negative electrode coated with a polymer on the life performance of the capacitor, the cell placed in an aluminum sealed container with a valve and a pressure sensor (FP101A-D, Yokogawa Electric Corp.) was made as shown in Fig. 1. The capacitor cell was composed of the $130 \mathrm{~mm} \times 70 \mathrm{~mm}$ positive and negative electrodes with a $30 \mathrm{~mm} \times 10 \mathrm{~mm}$ tab, which were prepared by coated with the mixture of the active materials on the both sides of etched Al, the separators, and our electrolyte.

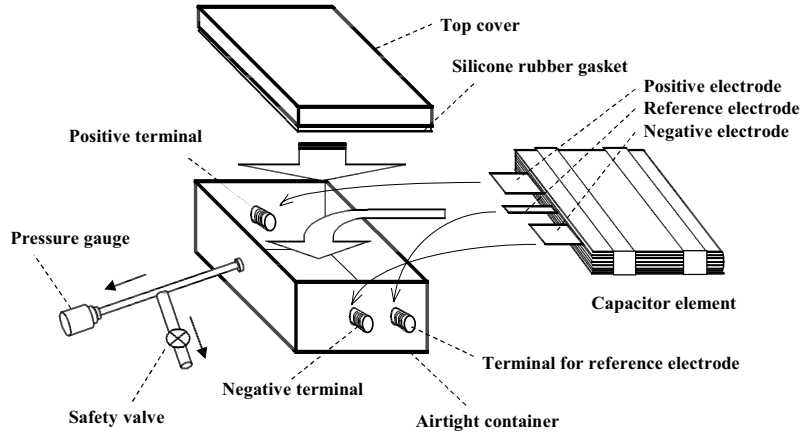

Fig. 1 Illustration of an electric double layer capacitor sample and an experimental apparatus with an airtight container and a pressure gauge.

The negative electrode was dipped into an aqueous dispersion of polytetrafluoroethylene (PTFE) and dried. By repeated this several times, the amount of PTFE coating the negative electrode was controlled. The cellose separator as a conventional, the polyethylene film separator, and the developing separator were used.

The life performance test of the capacitor sample as the float charge of $3.0 \mathrm{~V}$ at $70^{\circ} \mathrm{C}$ or $80^{\circ} \mathrm{C}$ was carried out with measuring the internal pressure.

\section{RESULTS AND DISCUSSION}

\subsection{Study and Development for High Performance of the EDLC}

\subsubsection{Development of the Ionic Liquid as an Electrolytic Salt}

When the capacitor is ideally charged or discharged at a current, i, for a time, dt, the charged or discharged capacity, $\mathrm{dQ}$, is given by:

$$
\mathrm{dQ}=\int \mathrm{idt}=\mathrm{CdV}
$$

where $\mathrm{C}$ is the electrostatic capacitance of the capacitor and $\mathrm{dV}$ is the voltage change during the charge or discharge [18]-[19]. The capacity depends on the number of ions adsorbed on or desorbed from the electrodes. Therefore, the storage capacity can have a limit by the number of ions in the electrolyte. The 
concentration of the electrolyte might have to be higher for increasing the energy of the capacitor by using an active material with a higher surface area and by charging at a higher voltage.

The solid such as the quarternary ammonium salt have been dissolved to the solvent such as propylene carbonate for the electrolyte for the capacitor. Recently, the ionic liquid is expected to use as an electrolytic salt for increasing the energy density of the capacitor and extending its life. Because the ionic liquid is a liquid at the normal temperature and can be blended in many organic solvents at any concentration, we do not need to mind the solubility of the solid salt to the solvent. While some imidazolium salts and some pyridinium salts are known well as ionic liquids, the electrolyte with them does not have a wide potential window and can be hardly used to the capacitor at a higher voltage [14]-[15].

We developed the ionic liquid with a wide potential window. The ionic liquid is a quarternary ammonium salt, N, N-diethyl-N-methyl-N-(2-methoxyethyl) ammonium tetrafluoroborate $\left(\mathrm{DEME}-\mathrm{BF}_{4}\right)$. Two ethyl groups are substituted to a methyl group and a methoxyethyl group in tetraethylammonium tetrafluoroborate $\left(\mathrm{TEA}-\mathrm{BF}_{4}\right)$ which is often used as the quarternary ammonium salt for the capacitor. DEME$\mathrm{BF}_{4}$ has the chemical structure similar to $\mathrm{TEA}-\mathrm{BF}_{4}$ and is liquid. Voltammetry of the platinum electrode carried out in some electrolytes. The cyclic voltammograms of

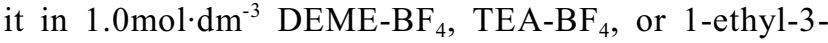
methylimidazolium tetrafluoroborate $\left(\mathrm{EMI}^{\left.-\mathrm{BF}_{4}\right)}\right.$ propylene carbonate solution are shown in Fig. 2. The reduction potential at ca. $-3.2 \mathrm{~V}$ vs. $\mathrm{Fc} / \mathrm{Fc}^{+}$in the DEME- $\mathrm{BF}_{4}$ solution was more base than at ca. $-2.0 \mathrm{~V}$ vs. $\mathrm{Fc} / \mathrm{Fc}^{+}$in the EMI-BF $\mathrm{E}_{4}$ solution. The oxidation potentials in the electrolytes were deference while we expected them to have the same potential as an electroxidation of $\mathrm{BF}_{4}^{-}$or/and propylene carbonate. This may be for existence of the impurities or interaction with the cation. On the whole, we got an electrolyte that can give many ions and has a wide potential window.

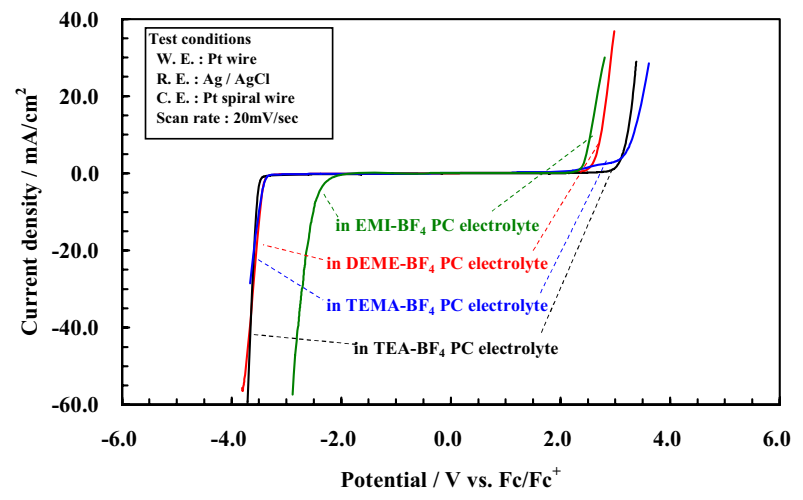

Fig. 2 Cyclic voltammograms of Pt electrode in the various electrolytes. DEME- $\mathrm{BF}_{4}, \mathrm{EMI}-$ $\mathrm{BF}_{4}, \mathrm{TEMA}_{-} \mathrm{BF}_{4}$, and TEA-BF 4 were used as an electrolyte salt.
However, the concentration of the electrolyte was found to have an influence on the life of the capacitor. The discharge energy changes of the capacitor with the some concentrations of the electrolyte in the float charge were shown in Fig. 3. It was found that the capacitor with low concentration of electrolyte has a long life. The rate of the undesirable side reaction on the electrode may have decelerated in low concentration of electrolyte. An appropriate concentration of electrolyte was chosen for our produced capacitor because there is a trade-off between the energy density and the life performance on the electrolyte concentration.

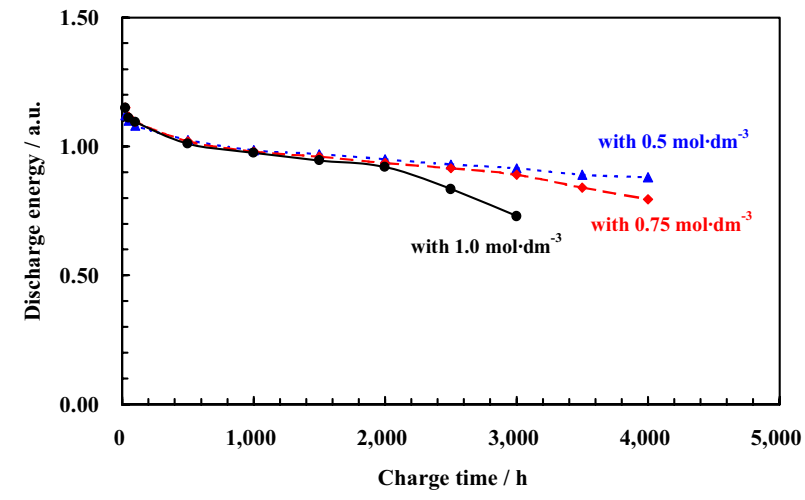

Fig. 3 Discharge energy changes of the capacitor with the some concentrations of the electrolytes in the float charge at $3.0 \mathrm{~V}$ and $70^{\circ} \mathrm{C}$.

\subsubsection{Study of the Activated Carbon as Positive and Negative Active Materials}

Activated carbon was studied as an active material of the capacitor. The capacitance in the equation (1) depends on the surface area of the active material. The active material with a large surface area is necessary for increasing the capacitance of the capacitor. When the capacitor is charged, the electrons flow from the positive electrode to the negative electrode through the external circuit. The active material can be electroxidized on the positive electrode and electroreduced on the negative electrode at some potential. Besides it, because the anion and the cation were different in the size, mobility, and the other characteristics, the different activated carbons should be used for the positive and negative active materials, respectively.

We investigated the positive and negative capacitances and the life performances of the capacitor with the various specific surface areas of activated carbons. The positive and negative capacitances were calculated by differentiating the discharge capacity with respect to the potential. The relation between the specific surface area of the activated carbon and the positive or negative capacitance was shown in Fig. 4. The capacitance increased with an increase in the specific surface area of the activated carbon as discussed in the report [20]. 


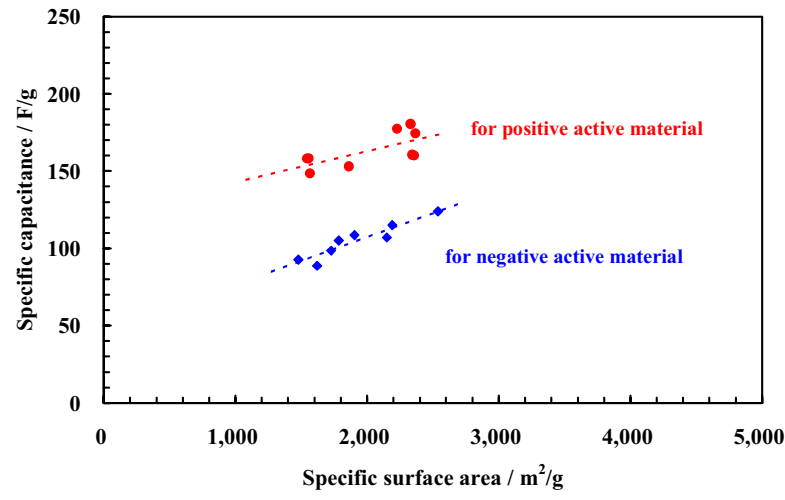

Fig. 4 Relation between the specific surface area of the activated carbon and the positive or negative capacitance.

However, the activated carbon with a large surface area may not be chosen for the long life of the capacitor. The lifetime for which $60 \%$ of the discharge energy of the capacitor in the float charge test could be maintained was shown in Fig. 5. The surface area of the activated carbon as the positive material did not depend on the lifetime. The lifetime with the activated carbon with a small surface area for the negative material was found to be long. Therefore, the one with a large surface area can be used as a positive material and the other with appropriate surface area for the life should be used as a negative material for our produced capacitor.

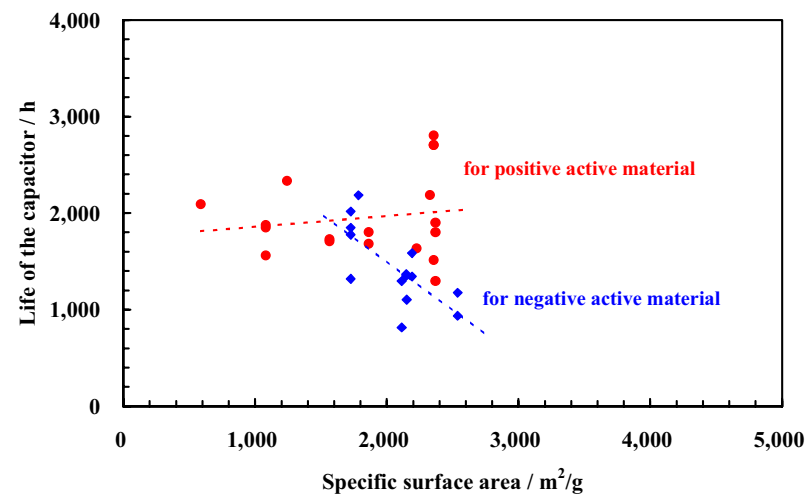

Fig. 5 Relation between the specific surface area of the activated carbon and the life of the capacitor in the float charge test at $3.0 \mathrm{~V}$ and $70^{\circ} \mathrm{C}$. The time for which $60 \%$ of the discharge energy of the capacitor was maintained was plotted as the life of it.

\subsubsection{Other Trials for Extending the Life of the EDLC}

Because gas is generated in the capacitor during the charge, it is expected that controlling the undesirable reactions can extend its life. The negative electrode was coated with a polymer for controlling its corrosion and the side reaction to investigate the life performance of the capacitor with it. The life of the capacitor samples with the negative electrodes coated with PTFE was shown in Fig. 6. The amount of PTFE coated on the negative electrodes of the capacitor samples is indicated to increase in order of square, diamond, triangle, and christcross. It was found that the capacitor with the negative electrode coated with a heat-stable binder or a corrosive resistant material had a longer performance. It is expected that a corrosive resistant metal will be used for the negative.

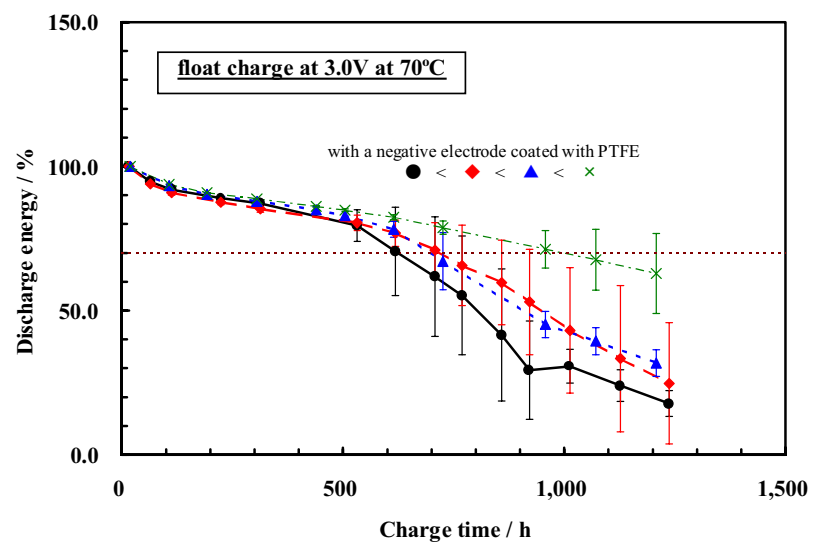

Fig. 6 Discharge energy change of the capacitor samples with coated negative electrode during the float charge at $3.0 \mathrm{~V}$ and $70^{\circ} \mathrm{C}$.

Separator affected on the undesirable side reactions with gas generation in the charge of the capacitor. Test results with three kinds of separator are shown in Fig. 7. $\mathrm{A}, \mathrm{B}$, and $\mathrm{C}$ are the cellose separator as a conventional, the polyethylene film separator, and the developing separator, respectively. Gas generated in the float charge of the capacitor sample with the separator A increased. The internal pressure of the capacitor samples with the separator B and C was controlled well, and its life performances became longer. It suggested that the reaction with gas generation in the charge of the capacitor caused the potential changes and influenced the life performance of the capacitor. B was used as the separator of the N's Cap.

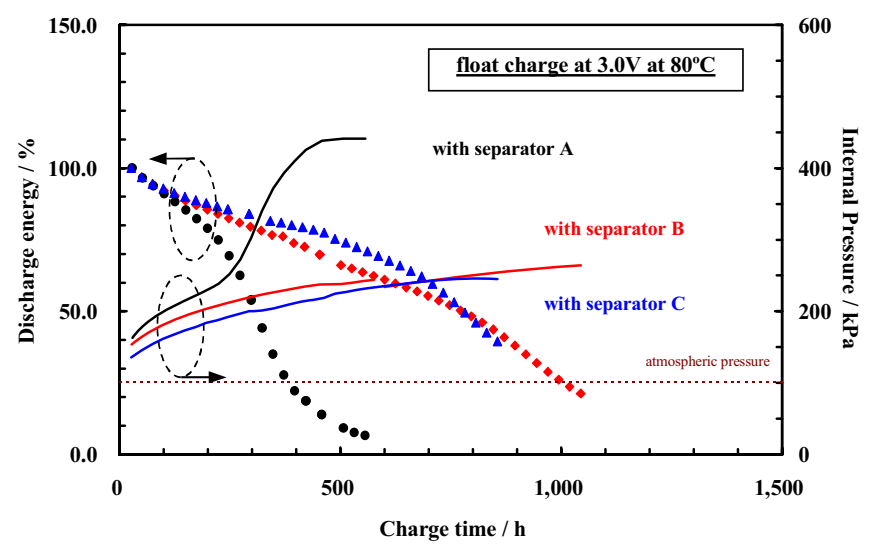

Fig. 7 Discharge energy and internal pressure changes of the capacitor samples with some separators during the float charge at $3.0 \mathrm{~V}$ and $80^{\circ} \mathrm{C}$. 


\subsection{Nisshinbo Electric Double Layer Capacitor, "N's Cap"}

\subsubsection{High Power and Long Life Capacitor Cell}

We have developed the EDLC, "N's Cap", with the ionic liquid, the activated carbons which have appropriate specific surface areas for the positive and negative electrodes, and the separator, and by arranging an element design as a new product [13]-[14], [21]. Its lineup includes three types of capacitor cells with rated capacitance of $250 \mathrm{~F}, 500 \mathrm{~F}$, and $1,000 \mathrm{~F}$. The appearance for them and the specifications for one with 1,000F are shown in Fig. 8 and Table 1, respectively. N's Cap has a rated voltage of $3.0 \mathrm{~V}$ and an internal resistance of $0.7 \mathrm{~m} \Omega$ that is equivalent to ca. $0.8 \Omega \mathrm{F}$. The value is hardly obtained in relevant capacitors with an activated carbon and an organic electrolyte.

(a)

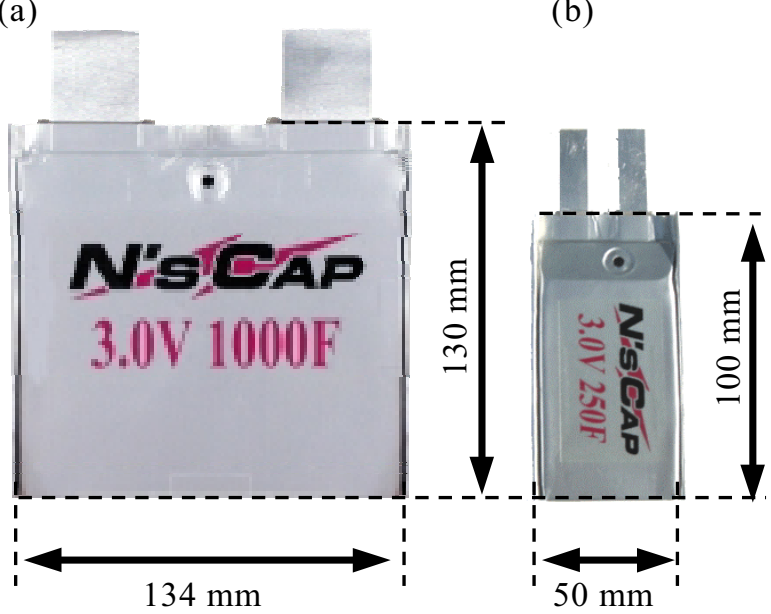

$\mathrm{t}=9.2 \mathrm{~mm}(1,000 \mathrm{~F}$ and $250 \mathrm{~F}), 5.4 \mathrm{~mm}(500 \mathrm{~F})$

Fig. 8 Lineup and appearances of the N's Cap for $1,000 \mathrm{~F}$ and $500 \mathrm{~F}$ type (a) and for $250 \mathrm{~F}$ type (b).

Table 1 Specifications of the N's Cap (1,000F type)

\begin{tabular}{|c|c|c|}
\hline Quantity & Unit & Value \\
\hline Rated voltage & $/ \mathbf{V}$ & 3.0 \\
\hline Rated capacitance & $/ \mathbf{F}$ & $1,000^{+20}$ \\
\hline Specific power ${ }^{1)}$ & / W/kg & 7,900 \\
\hline Power density ${ }^{1)}$ & $/ \mathbf{W} / \mathbf{l}$ & 10,800 \\
\hline Specific energy ${ }^{2)}$ & / Wh/kg & 7.5 \\
\hline Energy density ${ }^{2)}$ & $/ \mathbf{W h} / \mathbf{l}$ & 10.7 \\
\hline Internal Resistance ${ }^{3)}$ & $/ \mathrm{m} \Omega$ & 0.7 \\
\hline Life $^{4)}$ & $/ \mathbf{h}$ & $>2,000$ \\
\hline Temperature & $1{ }^{\circ} \mathrm{C}$ & $-30 \sim+60$ \\
\hline Volume & / cc & 132 \\
\hline Weight & $/ g$ & 199 \\
\hline
\end{tabular}

1) as calculated at the SOC of $50 \%$

2) as calculated from discharge energy down to $0.0 \mathrm{~V}$

3) as substituted for impedance at $1,000 \mathrm{~Hz}$

4) in the float charge at $60^{\circ} \mathrm{C}$
Especially, the power density of the N's Cap is about $10,000 \mathrm{~W} / 1$ and its value is the maximum level in the industry. Life performance of the N's Cap is shown in Fig. 9. The N's Cap has a life performance [22]-[23] for over $1,000 \mathrm{~h}$ at $70^{\circ} \mathrm{C}$ and for over $2,000 \mathrm{~h}$ at $60^{\circ} \mathrm{C}$ as it is able to keep $80 \%$ of its storage energy to a rated energy.

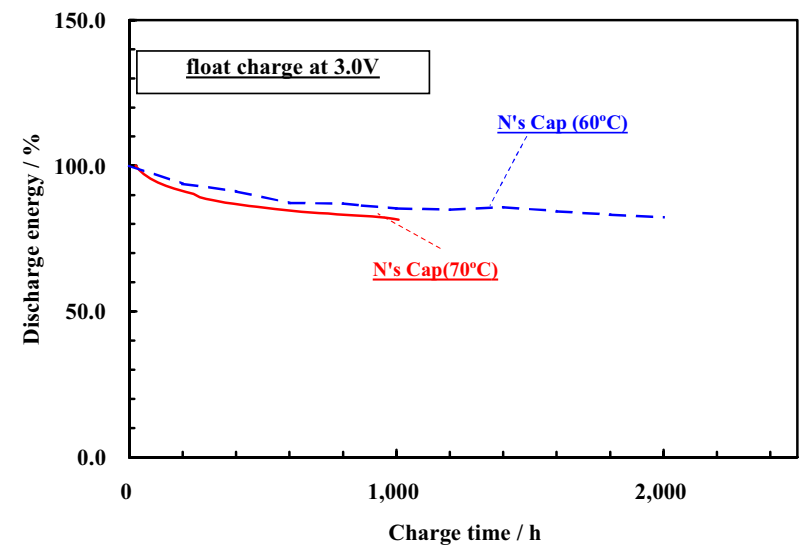

Fig. 9 Life performances of the N's Cap in the float charge at the constant voltage of $3.0 \mathrm{~V}$ at $70^{\circ} \mathrm{C}$ and $60^{\circ} \mathrm{C}$.

\subsubsection{Nisshinbo and JRC Capacitor Modules}

An assembled battery made by connecting the EDLC cells or Li-ion cells containing organic electrolyte in series does not have any mechanism to equalize the state of charge of each cell like a sealed $\mathrm{Pb}$-acid battery and sealed Ni-MH battery with aqueous electrolytic solution. Therefore, an external circuit is required to allow equalization of the state of charge for each cell of the storage devices with organic electrolyte.

Nisshinbo Industries Incorporated and Japan Radio Corporation Limited (JRC) have developed the external circuit [24]. The circuit is shown in Fig. 10a and 10b. It is equipped with coils and FET switches, a circuit in which a coil and a switch are connected in series and connected with the capacitor in parallel. And each state of charge of the capacitor cells can be equal by controlling the equalization of each voltage of the coils. The external circuit is compact and has a low energy loss. We have a various types of capacitor modules with the external circuit and with a rated voltage from $15 \mathrm{~V}$ to $400 \mathrm{~V}$ to match the requirements of customers as shown in Fig. 10c.

The N's Cap modules have been equipped with another convenient function. A unit made by some modules connected in series has to equalize the state of charges of each module. The N's Cap module is equipped with two terminals we call "EQL". Equalizing the states of charge of the modules can be made by only connecting the EQL terminal of a module with one from another module. This convenience is one of the good characteristics of the N's Cap. 
(a)

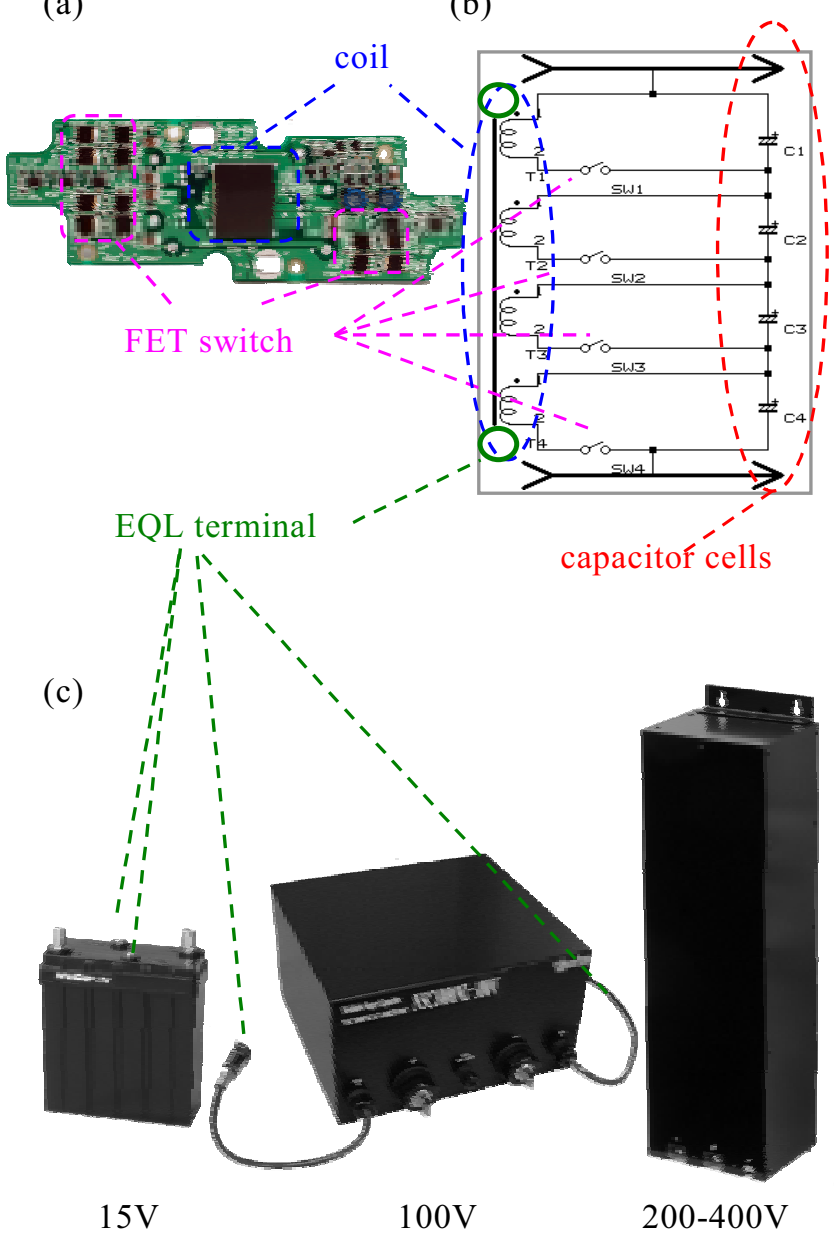

Fig. 10 Appearance of the external circuit to balance cell voltages (a), illusutation of its circuit diagram (b), and lineup of the capacitor modules (c).

\subsubsection{Application of the N's Cap Modules for EV}

A storage unit composed of seven N's Cap modules with the rated voltage of $15 \mathrm{~V}$ connected in series was used in a driving test of the electric vehicle, "COMS", we call "C-COMS". A photograph of the C-COMS used in the test is shown in Fig. 11. The C-COMS with N's Cap modules can run for about $20 \mathrm{~min}$ by 1 -min. charge, while the "COMS" with an as received $\mathrm{Pb}$-acid battery can run for about 40-80 min after $8 \mathrm{~h}$-charge [25]. This is an application in which the N's Cap can be rapidly charged.

\subsubsection{Examination for a Hybrid Storage Unit with Battery and EDLC}

The EDLC, although its storage energy is too low to apply to EVs, is expected to enhance the lifetime of a secondary battery. We attempted to use a hybrid storage unit which consists of the EDLC and a chemical secondary battery connected in parallel [26]-[27]. By way of example, the discharge and charge cycle pattern of a hybrid storage unit using three $15 \mathrm{~V}$ N's Cap modules and a B19-size valve regulated lead-acid (VRLA) battery was examined. Fig. 12a shows the cycle pattern, which was programmed for simulating a pattern for driving HEVs with idling, assisted acceleration, and/or regeneration by braking. The energy efficiency of the hybrid unit along with that for a VRLA is shown in Fig. 12b, which demonstrates explicitly that the energy efficiency for the hybrids unit with a VRLA and N's Cap exceeded that with the sole VRLA system.

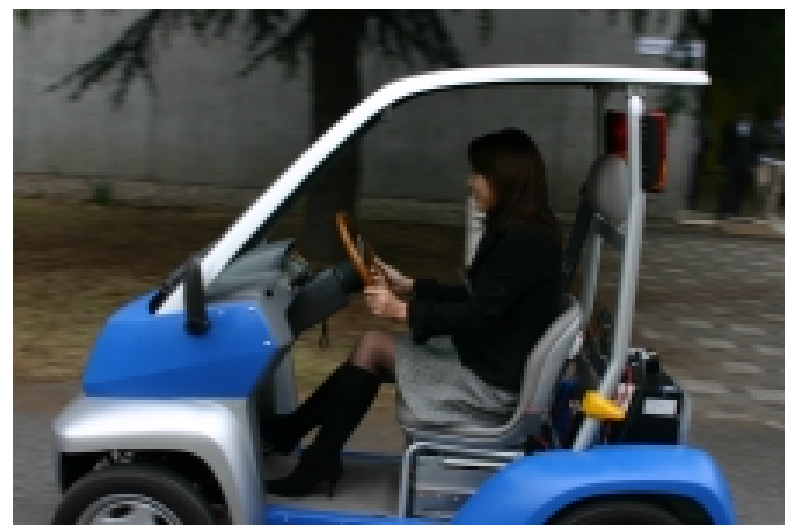

Fig. 11 Photograph of an electric vehicle "CCOMS" change of a hybrid battery using a storage unit assembled with seven $15 \mathrm{~V}$ N's Cap modules for a driving test by the Hori Laboratory at the Institute of Industrial Science, the University of Tokyo. (as obtained first-person informed consent)
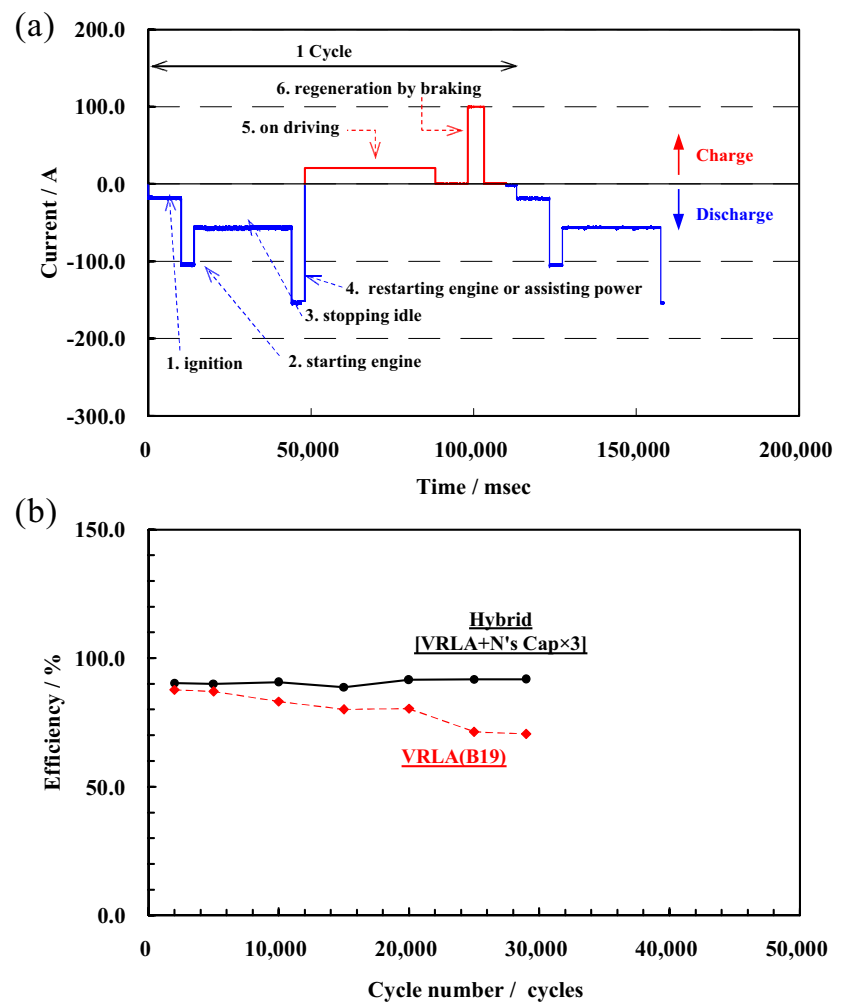

Fig. 12 A discharge and charge cycle pattern (a) and efficiency changes (b) in the examination for the application of the N's Cap modules. 


\section{CONCLUSIONS}

The ionic liquid was developed as an electrolyte salt to be able to give the EDLC the high energy density and the long lifetime in the future. The activated carbons with several specific surface areas were studied for the positive and negative active materials. It was found that the activated carbon with the large surface area as a positive active material and the one with the appropriate surface area gave the EDLC a high capacitance and a long life, respectively. We developed the EDLC as a new commodity, N's cap, with the ionic liquid and the activated carbons.

Various separators were studied for extending the lifetime of the EDLC because they influenced the increase of the internal pressure of it with gas generation. The polyethylene film separator was found to give the EDLC a lower internal pressure and a longer life to be used to our product. The other techniques such as coating the negative electrode with the polymer and using the developing separator were expected for getting a longer lifetime of the EDLC in the future.

The N's Cap developed through these studies has a high energy density, a high power density, and a long life with the rated voltage of $3.0 \mathrm{~V}$. We also developed the capacitor module assembled with many cells connected in series with an external circuit for equalizing the state of charge of them and are producing it as the storage device with a good performance and a convenient facility.

\section{ACKNOWLEDGEMENTS}

The authors thank to Mr. M. Nakanishi and Mr. K. Takagi of our group for their assistance in the making of the EDLC samples and data measurements.

The authors gratefully thank to Prof. Yoichi Hori and the personnel in the Hori Laboratory, the Department of Electrical Engineering, the University of Tokyo, for using our "N's Cap" modules for development of the electric vehicle "C-COMS".

\section{REFERENCES}

[1] M. Okamura, H. Hasuike, $M$ Yamagishi, and $\mathrm{S}$ Shuuichi: "A Status Report on the Power Storage System of Capacitor-Electronics", Electrochemistry, Vol.69, pp.414-421, 2001.

[2] A. D. Pasquier, I. Plitz, S. Menocal, and G. Amatucci: "A comparative study of Li-ion battery, supercapacitor and nonaqueous asymmetric hybrid devices for automotive applications", J. Power Sources, Vol.115, pp.171-178, 2003.

[3] B. S. Trasatti and P. Kurzweil: "Electrochemical Supercapacitors as Versatile Energy Stores", Platinum Metals Rev., Vol.38, pp.46-56, 1994.

[4] B. E. Conway: "The solvation factor in specificity of ion adsorption at electrodes", Electrochimica Acta, Vol.40, pp.1501-1512, 1995 .

[5] Y. O. Choi, K. S. Yang, and J. H. Kim: "Electrode of Electric Double Layer Capacitor Prepared from Densified Activated Carbon Fiber", Electrochemistry, Vol.69, pp.837-842, 2001

[6] K. Matsukawa, K. Kato, Y. Nakahara, K. Nishimura, and M. Kimoto, JP. Pat., Published Application, 2004-74,933,
2004.

7] M. Nakumura and R. Nozu, U.S. Pat., Published Application 2006-0,007,637, 2006.

[8] J. Gamby, P. L. Taberna, P. Simon, J. F. Fauvarque, and M. Chesneau: "Studies and characterisations of various activated carbons used for carbon/carbon supercapacitors", J. Power Sources, Vol.101, pp.109-116, 2001.

[9] A. Yoshida, I. Tanahashi, and A. Nishino: "Effect of concentration of surface acidic functional groups on electric double-layer properties of activated carbon fibers", Carbon, Vol.28, pp.611-615, 1990.

[10] J. P. Zheng, J. Huang, and T. R. Jow: "The Limitations of Energy Density for Electrochemical Capacitors", $J$. Electrochem. Soc., Vol.144, pp.2026-2031, 1997.

[11] D. Que: "Studies of the activated carbons used in double-layer supercapacitors", J. Power Sources, Vol.109, pp.403-411, 2002.

[12] J. H. Jang, S. Han, T. Hyeon, and S. M. Oh: "Electrochemical capacitor performance of hydrous ruthenium oxide/mesoporous carbon composite electrodes", J. Power Sources, Vol.123, pp.79-85, 2003.

[13] T. Sato, T. Maruo, S. Marukane, and K. Takagi: "Ionic liquids containing carbonate solvent as electrolytes for lithium ion cells", J. Power Sources, Vol.138, pp.253$261,2004$.

[14] T. Sato, G. Masuda, and K. Takagi: "Electrochemical properties of novel ionic liquids for electric double layer capacitor applications", Electrochimica. Acta., Vol.49, pp.3603-3611, 2004

[15] A. Lewandowski and M. Galiski: "Carbon-ionic liquid double-layer capacitors", J. Physics and Chemistry of Solid, Vol.65, pp.281-286, 2004.

[16] R. Nozu, M. Nakamura, K. Banno, T. Maruo, and T. Sato: "Studying a Phenomenon during Overcharge of a Lithium-Ion Battery with Methacrylate Additives for the Gel Electrolyte", J. Electrochem. Soc., Vol.153, pp.A1031-A1037, 2006.

[17] M. Okamura, "Electric Double Layer Capacitor and Storage Electricity System" Published by NikkanKogyo-Shinbun-sha, pp.106-112, 1999.

[18] S. Trasatti and P. Kurzweil: "Electrochemical Supercapacitors as Versatile Energy Stores", Platinum Metals Rev., Vol.38, pp.46-56, 1994.

[19] B. E. Conway: "Similarities and Differences between Supercapacitors and Batteries for Elecrtical Energy Storage", J. Power Sources, Vol.15, pp.65-81, 1995.

[20] I. Tanahashi, A. Yoshida, and A. Nishino: "Comparison of the Electrochemical Properties of Electric DoubleLayer Capacitors with an Aqueous Electrolyte and with a Nonaqueous Electrolyte", Bull. Chem. Soc. Jpn., Vol.63, pp.3611-3614, 1990.

[21] T. Sato: "Electric Double Layer Capacitor using Ionic Liquids as Electrolytes", Electrochemistry, Vol.72, pp.711-715, 2004

[22] M. Nakamura, M. Nakanishi, and K. Yamamoto: "Influence of physical properties of activated carbons on characteristics of electric double-layer capacitors", $J$. Power Sources, Vol.60, pp.225-231, 1996.

[23] R. Kötz, M. Hahn and R. Gallay: "Temperature behavior and impedance fundamentals of supercapacitors", $J$. Power Sources, Vol.154, pp.550-555, 2006.

[24] K. Yamashita, JP Pat., Published Application 2004$129455,2004$.

[25] K. Kawashima, T. Uchida, and Y. Hori: " Manufacturing of Small Electric Vehicle driven only by Electric Double Layer Capacitors for Easy Experiment of Vehicle Motion Control", EVS-21, 2004.

[26] G. Sikha and B. N. Popov: "Performance optimization of a battery-capacitor hybrid system", J. Power Sources, Vol.134, pp.130-138, 2004

[27] L.T. Lam and R. Louey: "Development of ultra-battery for hybrid-electric vehicle applications", J. Power Sources, Vol.158, pp.1140-1148, 2006. 


\section{BIOGRAPHIES}

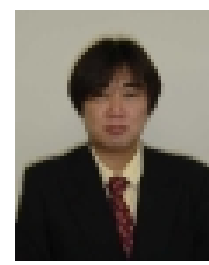

Ryutaro Nozu received a Master degree in Chemistry from Aoyamagakuin University in 1996. He was working as an engineer of secondary batteries in Furukawa Battery Co., Ltd. From 1996-2000 and Nisshinbo Industries Incorporated from 2001. He is now researching and developing an EDLC and secondary batteries for practical applications with a competent knowledge of electrochemistry, analytical chemistry, and cell designing.

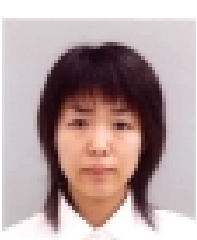

Mami Nakamura graduated from Tsuruoka National Collage of Technology in 2001.

She is now researching and developing an EDLC in Nisshinbo Industries Incorporated from 2001.

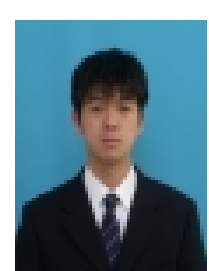

Yutaka Matsuzawa received a Master degree in Electrical \& Electronic from Shinsyu University in 2005. He was working as an engineer of EDLC in Nisshinbo Industries Incorporated from 2005. $\mathrm{He}$ is now researching and developing an EDLC with a competent knowledge of carbon materials and electrochemistry.

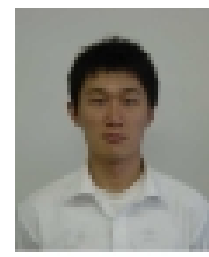

Kunihiro Mitsuya graduated from Shibaura Institute of Technology in 2005.

$\mathrm{He}$ is now researching and developing an EDLC in Nisshinbo Industries Incorporated from 2005.

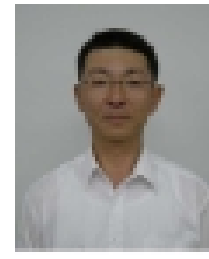

Toshiaki Kushihara received B.C. degree in Mechanical Engineering from the University of Tokyo in 1984. He joined Nisshinbo Industries Incorporated, Mechanical Engineering Headquarters in 1984. He was working as a developing engineer of the metal cutting machine tool during 1984-2003. In 2003, he moved to the Research \& Development Center as a marketing manger of the EDLC. In 2004, he became a manager of the development division of the EDLC. 